\title{
Student Retention Dialogue: Focus Group Outcomes
}

\author{
Ingrid St. Omer, Joanne Hood, Fonda Swimmer \\ Northern Arizona University
}

\author{
Elizabeth Bahe \\ Scottsdale Community College
}

\begin{abstract}
$\underline{\text { Abstract }}$
In the Fall of 2001, the Admissions, Recruitment and Retention committee at Northern Arizona University's (NAU) College of Engineering \& Technology (CET) sought to begin to collect data regarding student persistence. NAU has demonstrated a strong commitment to undergraduate education and diversity. According to the National Association of Minority Engineering Program Administrators (NAMEPA) 2001 Data Book, NAU ranks second in enrollment of Native American students in programs granting Bachelor of Science degrees in engineering, engineering technology, and computer science. At present, the population of Hispanic students within the College is approximately $6 \%$ and women represent $15 \%$ overall. The preliminary data is based on both formal and informal requests for information from students. According to current NAU policy, students are not required to participate in an "exit interview" with their advisor or department when they change majors or leave the university. A change of major form only seeks to ensure that the student is accepted into the new department and assigned an advisor. Thus, only anecdotal information was available since no formal mechanism existed to collect this data. In order to obtain data on why students leave the College, we undertook two initiatives. Students were contacted via e-mail to ask if they would provide the reason(s) why they left the majors. Additional information came from focus groups conducted with current students during the Fall 2001 semester. The participating students were very candid and specific, providing information on why they have persisted, as well as the reasons why other students they know have left the College. The students also offered suggestions on administrative and academic issues that may increase retention rates. As a result of the student input, the College has implemented a series of programs entitled "CET Connects" to try and improve student persistence. The content and reception of the programs by the student body will also be discussed.

\section{Introduction}

Northern Arizona University (NAU) is a premier residential university with a longstanding commitment to undergraduate teaching. Strong scholarly activities are emphasized to ensure excellence in teaching and a dynamic intellectual community. On and off-campus programs enroll approximately 19,000 students. Northern Arizona University's commitment to diversity is exemplified in its continued efforts to expose students, faculty and staff to diverse cultures, lifestyles and values. Since 1997, the total student population (Fall 1997-2001) has shown a steady increase in the percentage of ethnic minority students (African-American, AsianAmerican, Hispanic, and Native American students). In 2001, the percentage of ethnic minorities at NAU increased from $18.6 \%$ in 1997 to $21.1 \%$. NAU is centrally located relative to several Indian nations, including the Navajo Nation, the Hopi Nation, the Hualapai Tribe and others.
\end{abstract}


The College of Engineering \& Technology (CET) is the winner of the 1999 Boeing Outstanding Educator Award in recognition of our design sequence, Design4Practice. The Design4Practice sequence, taken by all students, is composed of a series of highly integrated design courses that span their program of study. This practice-oriented engineering curriculum, crafted with extensive input from industry, is built around a four-year interdisciplinary sequence of design courses that introduce students to the design process early in their college careers, while increasing the complexity of design challenges throughout the four years of study. Strong emphasis is placed on modeling real-world design scenarios: students work in interdisciplinary teams, interact with a client, and professionally present results. The College offers ABETaccredited Bachelor of Science programs and Master of Engineering programs in Computer Science and Engineering, Electrical Engineering, Civil Engineering, Environmental Engineering and Mechanical Engineering. The Master of Engineering program, oriented towards practicing professionals, is a unique collaboration with the University of Arizona and Arizona State University. Current student demographics within the CET differ slightly in composition from the overall university population. For Fall 2002, the CET student population was approximately $74 \%$ White, 12\% Native American, 6\% Hispanic, 5\% International, 2.1\% Asian American, 1\% African American, and $15 \%$ female students respectively.

Decreasing enrollment has been observed at both the college and university level prompting additional focus on recruitment and retention issues. A comprehensive evaluation of university and college climate and recruitment and retention activities prepared by Scott Healy and Associates revealed a five-year average retention rate of $65 \%$ and $63 \%$ for NAU and CET respectively. CET also appeared to exhibit a downward trend in first-year retention.

In response to these concerns, the CET Admissions, Recruitment and Retention (ARR) committee sought to begin to collect more detailed data regarding student persistence. The preliminary data presented is based on both formal and informal requests for information from students. According to current NAU policy, students are not required to participate in an "exit interview" with their advisor or department when they change majors or leave the university. A change of major form only seeks to ensure the student is accepted into the new department and receives a faculty advisor assignment. Thus, only anecdotal information was available since no formal mechanism existed to collect this data. In order to obtain data on why students leave the College, we undertook two initiatives. Students were contacted via e-mail to ask if they would provide the reason(s) why they left the majors. Additional information came from focus groups conducted with current students during the Fall 2001 semester. The participating students were very candid and specific, providing information on why they have persisted as well as why others they know have left the College. The students also offered suggestions on administrative and academic issues they believe will increase retention rates. As a result of the student input, the College has implemented a series of programs entitled "CET Connects" to try and improve student persistence. The content and reception of the programs by the student body will also be discussed. 
Survey and Student Records

Twenty percent of the students who changed majors during the time period between October 2001 and April 2002 were female, thus indicating that we were losing female students at a rate disproportionate to the total population in the College. A closer examination revealed that the CET is losing twice as many women as men from the Computer Science and Engineering (CSE) major. Preliminary results also indicate that the College is not losing minority students at a higher rate than the overall population in CET. The overall minority rate in the CET at the time of the Fall 2001 review of retention assessment was 24\%; the percentage of minority students who left their major was $21 \%$.

Twenty-eight percent of the students changed their major during their first semester of study, and thus, did not have an NAU grade point average. The cumulative grade point average of the remaining students ranged from 1.3 to 4.0 , with a mean of 2.80 . The majority, $65 \%$, of these students had a GPA of 2.5 or higher. Eighteen percent had a GPA between 3.0 and 4.0.

The number of semesters present in the CET ranged from one to nine, with a mode of 1 . Sixtythree percent of the students changed majors after less than 3 semesters in engineering.

Seventeen students responded to the e-mail request for information. Of the responses received, only two students indicated that they were not able to keep up with the coursework, or found it difficult. Several students found the work boring, or lost interest after working in internships or learning about engineering occupations and courses. One student had a particularly bad time with their advisor, and another had a math professor who soured his interest in engineering. A proposed aerospace certificate in partnership with another institution had attracted one student, however the certificate program never materialized. Another student indicated a desire to pursue medical school. Reducing time to graduation was also mentioned.

Responses from the e-mail survey, combined with the information gleaned from student records, were generally consistent with the broad scale of factors identified by Seymour. ${ }^{2}$ Despite the easy conclusion that students leave as a result of poor academic performance, qualified and able students left the College. Loss of interest, poor teaching and inadequacies in advising were the more common responses. In many cases, students are leaving the CET before they reach the core of the curriculum and develop a more comprehensive understanding of the engineering profession.

\section{Focus Groups}

The feedback received from the student focus groups provided a wealth of information about obstacles and potential strategies for removing these barriers. This was particularly true for female and Native American students. Two members of the ARR committee initiated a series of three focus groups. The sessions were conducted using a basic line of inquiry designed to elicit discussion, and are listed below.

- Comment on your Advising Experience

- What kept you in engineering? What makes it possible for you to stay?

- What difficulties have you or your peers encountered? 
- How would you describe you faculty/student interactions?

- What would you tell a freshman?

- What would you say has been a positive experience in the College?

- What might/could have made your experience better?

Several factors were common among the groups and the recommendations focus on these areas. The comments voiced were consistent with those observed and documented by Seymour and Hewitt, Rosser et. al., and Margolis and Fisher. ${ }^{3-5}$ The responses of the Native American students included additional information not generally reflected in the literature.

Fostering greater interaction between upper level and lower level students was discussed on many levels. In terms of formal structure, mentoring programs and membership in student organizations were mentioned several times as a means to provide a student support network. Creation of a student lounge with comfortable seating and reference materials was also discussed. The lounge would provide additional opportunities to foster collaboration in studying and obtain informal peer assistance. The sterile university environment and language heard in the hallways was of greater concern to the Native American students. The scarcity of women and minority faculty role models was also a concern for the underrepresented students.

Classroom issues touched on the lack of student familiarity with graphing calculators and other software tools, gender bias particularly in the selection of classroom examples and comments, precollege preparation (especially in math and computer programming), and the lack of faculty training. Students felt that many new faculty did not appear to have a clear understanding of how to teach the material or relate to students. In most cases, they were not questioning faculty knowledge but felt that there was little or no academic context provided for the material. Several students also expressed frustration with faculty availability during office hours and willingness to answer questions. The atmosphere described by these students when approaching faculty was that of intrusion, resigned obligation, or brusque dismissal.

The majority of students in all groups felt that a "tools" course incorporating software packages, practical professional training, time management, and an element of trial and error, would help students be more successful. Additionally, formal recitation sections were also thought to be a path to improved performance. Within the CET, approximately $18-20 \%$ of the students are on the deficiency list for receiving substandard grades in CET courses. An analysis of this list over a period of five semesters indicated that five 100 and 200 level courses account for the bulk of these problems. On average, $32 \%$ of the students in these courses received a D, an F, or withdrew. These are the courses that will be targeted for development of recitation sections that incorporate collaborative learning methods.

Faculty training also extended to the advising arena. Many students did not feel that their advisors had received sufficient training to answer their questions regarding the administrative issues such as registration, graduation, and scholarships. Additionally, students whose coursework falls primarily outside the College, i.e. freshmen and sophomores, felt disconnected from the advisement process. NAU is creating a centralized advising office for lower division and first semester transfer students that will begin for Fall 2003 students. For upper division students, 
e-mail distribution lists were suggested as a means to improve advising communication. Joanne Hood, Administrative Director of Academic Affairs for the CET, is developing a comprehensive manual for advising and has initiated training sessions for faculty. NAU's new Gateway Center will also be charged with creation of a university-wide advising manual and various training programs. Many students indicated that providing programs of study beyond the standard 4-year time frame would help them to better plan their academic path and assist with advising.

The discussion of persistence in the College reduced to two simple elements: determination and family support. In terms of difficulties encountered during their academic journey, the most unexpected responses came from the Native American students. These students did not feel that their retention was important to the CET. The physical appearance of the building was not anticipated as factor influencing persistence. Many of these students regularly commute distances of 75 miles or more to maintain family ties. Native American students are disproportionately likely to be single parents, have dependents, be financially independent of their parents, and enroll part-time part year round - all characteristics associated with reduced likelihood of degree completion. ${ }^{6}$ Financial issues (family, tribal scholarship constraints, and expensive textbooks) were of particular concern. Students often felt that they had spent money on books that were never utilized. Additionally, many of the Native American students felt that some of the obstacles were cultural. Getting beyond the "Dances with Wolves" image of indigenous people was indicated as an issue with both faculty and fellow students. The quiet/listening habits of their home environment, and preference for collaborative versus traditional individualistic learning methods make some of the classroom interactions challenging. ${ }^{7,8}$ In most classroom environments, assignments are meant to be completed individually and shared activity is discouraged, which is contrary to cultural emphasis on community and harmony.

\section{Current and Future Directions}

Retention efforts in the CET prior to the ARR activities consisted primarily of the Multicultural Engineering Program (MEP) and the New Student Orientation. The MEP program was developed in 1994 to increase the retention and graduation rates of students from traditionally underrepresented groups. MEP services include: a summer bridge program, supplemental academic advising, financial aid and career advisement, freshman college survival skills course, support for student groups, and tutoring program. The New Student Orientation Program was developed years ago as a fall-only program based on retention research emphasizing the importance of making "connections" early in the transition to college. The evaluations of the orientation program indicate that it is effective in assisting students with the transition. However, students are often overwhelmed during orientation and some information, although conveyed, is not fully digested. This program has been expanded to include Spring 2003 students and is now offered each semester.

A proposal to create a series of meal activities between faculty and students was amended due to unanticipated administrative changes within our college. The Dean and three of five department chairs changed during the summer of 2002, and there was inadequate time to discuss this program with the new staff in advance of planning activities for the Fall semester.

Instead, the College ARR Committee, chaired by the Administrative Director of Academic Affairs, created a four-part program, "CET Connects" to address many of the goals and the issues 
arising from the student focus groups. When paired with our highly successful New Student Orientation Program, these activities combine into the initial phase of a strategic retention program.

The specific components of "CET Connects" were as follows:

- Club/student organization Fair

- Getting Ready for Registration

- Resume Writing Workshop

- Academic Success Panel

Advertisement for these programs was done by posting flyers in the College, announcements made in 100-level construction management, CSE, and engineering classes, and an e-mail from the Administrative Director of Academic Affairs to the student list serve for freshmen in our majors. The activities were scheduled for 5:30 pm, at a time after the majority of classes, but ending with ample time for resident students to obtain dinner in the dining halls.

The first activity was a Club Fair, in which student clubs and professional societies set up table displays, and members were available at the tables to discuss their activities. The clubs were enthusiastic in their participation, since it gave them an opportunity to recruit new members for their clubs. Students attending the Club Fair were asked to complete an interest survey, from which we developed our next activities.

The following tally indicates the interest in the activities presented on the interest survey:

\author{
12: Internships discussion \\ 11: Munchies/study break during exam week \\ 11: Potluck during exam week \\ 9: Secrets to academic success \\ 7 : Study skills \\ 7 : Tools workshop: graphing calculator, excel, PowerPoint \\ 7 : Peer mentoring \\ 6: Time management \\ 4 : Preparing for graduate school \\ 4: Alumni panel to share college \& work experience \\ 0 : Liberal studies workshop
}

Our College student ambassadors have volunteered to coordinate and advertise this event each fall semester, as a means of increasing their own visibility as well as to assist the clubs in recruiting new members. Ideally, this will be scheduled earlier in the semester, preferably during the $2^{\text {nd }}$ or $3^{\text {rd }}$ class week. This initial offering occurred during the $5^{\text {th }}$ week of the semester.

Our second activity was "Getting Ready for Registration" which was timed to coincide with the start of the early registration period for spring semester. All CET students are required to meet 
with a faculty advisor prior to registering for classes for the next semester. Freshmen are unfamiliar with the advisement and registration process, and are unsure how to contact their faculty advisor, whom they may have never met before. The workshop was developed to familiarize students with the process, as well as to allay their uncertainties about how to prepare for their advisement meeting. The Administrative Director of Academic Affairs conducted this session. A formal evaluation of "Getting Ready" was conducted, and 78\% of the responses fell into the Good or Excellent category.

Students who attended the "Getting Ready" workshop were also informed about an upcoming conference, The Guaranteed 4.0 Learning System, which was being conducted by a national expert in improving student learning and academic performance. The Guaranteed 4.0 workshop was scheduled to be held for our NSF Scholarship holders, but the sponsor agreed that freshmen could be invited as well. Several of the "Getting Ready" participants took advantage of this opportunity, and attended this workshop.

The third activity, a Resume Writing Workshop, was also developed with the NSF scholars as the primary audience, but all freshmen were invited to attend. The topic was resume writing, and was conducted by one of the university Career Services Specialists.

The fourth "CET Connects" activity was an Academic Success Panel, held in November. Several junior and senior students who are members of Tau Beta Pi and Sigma Lambda Chi participated as panelists, answering prepared and impromptu questions about the success strategies they have developed during the course of their undergraduate academic career. The students presenting represented a variety of majors, and included topics related to internships, research, mentoring, and balancing multiple priorities including participating as a student athlete, and maintaining. The panel activity was considered to be very informative by those students in attendance. However, as this activity occurred during the week before the Thanksgiving break, it was not as well attended.

Several important lessons were learned from these initial activities. Timing is critical and it would be more effective to have the entire program scheduled prior to the start of the semester. This would allow the committee to advertise directly to students at New Student Orientation and possibly reach more of the sophomores. Although formal evaluations were conducted for some of the programs, this was not true for all activities. Some of the feedback came from informal discussions with participants.

Additional efforts will address those courses with which students are known to struggle, providing greater engineering profession context for underrepresented students, foster student support networks, and continued faculty development in terms of course content, awareness, and training.

\section{Conclusions}

The focus groups provided information that was consistent with many of the published findings but they also provided additional factors that were not anticipated. University efforts to improve retention tend to focus exclusively on students. This approach does not directly address 
institutional obstacles, cross-cultural communications barriers, low faculty expectations, etc. factors that contribute to the high attrition of students. Our findings indicate that involvement on both faculty and staff levels are necessary. Even if a program such as MEP or the New Student Orientation is effective, it deals largely with students, and it does not bring about permanent change in the institutional environment. ${ }^{9}$ Future focus groups, in combination with student records data, will help in determining the effectiveness of our retention strategy.

$\underline{\text { References }}$

Northern Arizona University, “2003 Strategic Plan”, PAIR Enrollment Highlights, pg. 9

${ }^{2}$ Seymour, Elaine, "Revisiting the 'Problem Iceberg': Science, Mathematics, and Engineering Students Still Chilled Out," Journal of College Science and Teaching, v. 24, n. 6, p. 392.

${ }^{3}$ Seymour, Elaine and Hewitt, Nancy M., Talking About Leaving: Why Undergraduates Leave the Sciences, (Boulder, Colorado: Westview Press, HarperCollins Publishers, Inc. 1997).

${ }^{4}$ Rosser, Sue V., eds., Teaching the Majority: Breaking the Gender Barrier in Science, Mathematics, and Engineering, (New York, NY: Teachers College Press 1995).

${ }_{5}^{5}$ Margolis, Jane and Fisher, Allan, Unlocking the Clubhouse: Women in Computing, (Cambridge, MA: The MIT Press 2002).

${ }^{6}$ National Center for Education Statistics (NCES). 1998a. American Indians and Alaska Natives in Postsecondary Education. By D. Michael Pavel, Rebecca Rak Skinner, Elizabeth Farris, Margaret Cahalan and John Tippeconnic. NCES 98-291. Washington, DC: U.S. Government Printing Office.

${ }^{7}$ Hilberg, R. Soleste and Tharp, Roland G., "Theoretical Perspectives, Research Findings, and Classroom Implications of the Learning Styles of American Indian and Alaska Native Students," IndianEduResearch.Net, EDO-RC-02-03, September 2002. February $2003<$ http://www.indianeduresearch.net/edorc02-03.htm>.

${ }^{8}$ Shutiva, Charmaine L., "Career and Academic Guidance for American Indian and Alaska Native Youth," IndianEduResearch.Net, EDO-RC-01-3, October 2001. February $2003<$ http://www.ael.org/eric/digests/Edorc013.htm>.

${ }^{9}$ National Action Council for Minorities in Engin eering (NACME). May 1993. Vol. 4, No. 1., "Research Letter: Minority Engineering Programs-A Case For Institutional Support.” By Catherine Morrison and Lea E. Williams.

INGRID ST. OMER is currently an Assistant Professor and Director of the Advanced Microelectronics Laboratory at Northern Arizona University. Prior to earning her doctorate, she worked in industry attaining the rank of Senior Engineer and Engineering Supervisor. Upon completion of the Ph.D. degree at the University of Missouri-

Columbia (MU), she served as a Visiting Assistant Professor in the MU Department of Electrical Engineering, and then as a Research Associate and President's Postdoctoral Fellow at the University of Minnesota.

JOANNE HOOD is the Administrative Director of Academic Affairs at Northern Arizona University College of Engineering and Technology.

FONDA SWIMMER, Navajo, is the Director of the Multicultural Engineering Program. A proud alumnus of Northern Arizona University, having attained her Bachelor's degree and Master's degree in Public Administration has worked in both a non-profit and academic environment at NAU for four years. Her work now centers on the enhancement and expansion of MEP student services. She thoroughly enjoys her work and seeing students succeed.

ELIZABETH BAHE is presently the Director of Native American Programs at Scottsdale Community College. She was the Director of the Multicultural Engineering Program at NAU during the 2001-2002 academic year. 